\title{
Pitting of Fe-Mn-Al Alloys in NaCl Solution
}

M Ruscak

Department of Materials Science and EngineeringNational Tsing Hua University Hsinchu, Taiwan, R.O.C.

T.P Perng

Department of Materials Science and EngineeringNational Tsing Hua University Hsinchu, Taiwan, R.O.C.

Follow this and additional works at: https://jmstt.ntou.edu.tw/journal

Part of the Engineering Commons

\section{Recommended Citation}

Ruscak, M and Perng, T.P (1993) "Pitting of Fe-Mn-Al Alloys in NaCl Solution," Journal of Marine Science and Technology. Vol. 1: Iss. 1, Article 1.

DOI: $10.51400 / 2709-6998.2471$

Available at: https://jmstt.ntou.edu.tw/journal/vol1/iss1/1

This Research Article is brought to you for free and open access by Journal of Marine Science and Technology. It has been accepted for inclusion in Journal of Marine Science and Technology by an authorized editor of Journal of Marine Science and Technology. 


\section{Pitting of Fe-Mn-Al Alloys in $\mathrm{NaCl}$ Solution}

\section{Acknowledgements}

This research was supported by the National Science Council of the Republic of China under Con-tract Nos. NSC 810405-E-007-12 and NSC 82-0405-E-007-052. The Femnal alloys were supplied by theAlloy Steel Laboratory, National Tsing Hua Univer-sity, Taiwan. 


\title{
PITTING OF Fe-Mn-AI ALLOYS IN NaCI SOLUTION
}

\author{
M. Rûscak and T.P. Perng \\ Department of Materials Science and Engineering \\ National Tsing Hua University \\ Hsinchu, Taiwan, R.O.C.
}

\begin{abstract}
Key words: $\mathrm{Fe}-\mathrm{Mn}-\mathrm{Al}$ alloys, corrosion, $\mathrm{NaCl}$ solution, pitting, ferrite, austenite, two-phase alloys.
\end{abstract}

\begin{abstract}
Five $\mathrm{Fe}-\mathrm{Mn}-\mathrm{Al}$ (Femnal) alloys with the ferrite contents varied from $0.5 \%$ to $98 \%$ were tested in $3.5 \% \mathrm{NaCl}$ at room temperature. Both potentiodynamic polarization and immersion test were performed. In deaerated solution, the corrosion potentials were very close for these alloys. The passive current increased and the width of the passive region decreased with the increase of ferrite content. However, the nearly ferritic alloy showed much better passivation behavior, presumably due to the addition of $6 \% \mathrm{Cr}$. In aerated solution, no or very small passive region was observed. From the immersion test, the general corrosion was found to be minor. Pitting corrosion was the primary corrosion except for the ferritic alloy. The pits were found more frequently in the ferrite phase or at the interface between the ferrite and austenite phases.
\end{abstract}

\section{INTRODUCTION}

Stainless steels based on the alloying elements of $\mathrm{Cr}$ and $\mathrm{Ni}$ are used worldwide in corrosive environments. Because of strategic character of both chromium and nickel, there raised some hope several years ago, when the new $\mathrm{Fe}-\mathrm{Mn}$-Al ternary alloys were introduced as the next possible candidate for corrosion applications.

As concluded from the comparison between Fe$\mathrm{Cr}-\mathrm{Ni}$ and $\mathrm{Fe}-\mathrm{Mn}$-Al alloys [1], the mechanical properties are comparable in a wide range of temperature - from cryogenic up to elevated. It has been confirmed that the Femnal alloys have superior creep resistance $[2,3]$. They also have good oxidation resistance up to $850^{\circ} \mathrm{C}$ [4-6]. Hydrogen embrittlement (HE) of the Femnal alloys has been reported [7-9]. The interface between austenite and ferrite was observed to be critical for the HE [8]. The measurement with a wide range of austenite/ferrite ratios showed that the degree of HE increased as the ferrite content increased. The alloy with a full austenite phase was essentially immune to HE [9]. As for the stress corrosion cracking (SCC) properties, it was observed that the ferritic phase and the interface along the ferrite and austenite were susceptible to the cracking in the solution containing $\mathrm{Cl}$ ions [10-11]. An anodic overpotential would lead to the decrease of the SCC susceptibility of the $\mathrm{Fe}-8.7 \% \mathrm{Al}-29.7 \% \mathrm{Mn}$ alloy [12]. The ability of passivation was found very poor for the same alloy if tested in $1 \mathrm{~N}$ sulfuric acid solution [13]. On the other hand, the general corrosion was found minor for the duplex Femnal alloys. Pitting was the main degradation factor [14]. Pits were observed mainly in the ferritic phase. A strong dependence of the electrochemical polarization on the concentration of $\mathrm{NaCl}$ has been reported [15]. The passive current density for Femnal alloys was higher than that for AISI 316 stainless steel by one order of magnitude $[14,16]$.

In the present work, the corrosion resistance of the femnal alloys was further studied. Alloys with the ratios of ferrite/austenite from $0.5 \%$ to $98 \%$ were tested in $3.5 \% \mathrm{NaCl}$ solution. The different corrosion characteristics of the ferrite and austenite phases were 
examined.

\section{EXPERIMENTAL}

The tests were carried out with five Femnal steels covering a wide interval of austenite/ferrite ratios. The chemical compositions of the alloys are given in Table 1 . The processing and typical microstructures of these alloys have been described previously [9]. Two experiments were performed in $3.5 \%$ $\mathrm{NaCl}$ solution at room temperature: electrochemical potentiodynamic polarization and immersion tests.

The potentiodynamic polarization curves were measured in both aerated and deaerated solutions. The test cell involved a gas bubbler, a saturated calomel reference electrode (SCE), and a graphite counter electrode. The specimens were ground by $\mathrm{SiC}$ paper to 1200 grit. The exposed area varied from 0.7 to $0.9 \mathrm{~cm}^{2}$.

The scanning rate was normally selected at $\operatorname{lm} V /$ s. Some additional measurements were conducted with the scanning rates of 0.2 and $10 \mathrm{mV} / \mathrm{s}$. For each condition, at least two specimens were used. In the case of deaerated condition, the solution was prebubbled for 24 hours and the bubbling continued during the test.

The immersion test was carried out in several 2-liter beakers. Specimens with the dimensions of $9 \mathrm{~mm} \times 9 \mathrm{~mm} \times 1.3 \mathrm{~mm}$ were tested. The surfaces of the specimens were ground to 1200 grit with $\mathrm{SiC}$ paper, cleaned, and dried. The lengths of immersion time were $2,4,7,14$, and 21 days. The specimens once taken out from the solution were not used for the next immersion. The surfaces of the specimens were sys-

Table 1. Chemical Compositions (Weight Percent) and Ferrite Contents of the Alloys

\begin{tabular}{lcrccc}
\hline Alloy & Mn & \multicolumn{1}{c}{ Al } & C & Cr & $\alpha$ (Pct) \\
\hline A & 28.52 & 9.97 & 1.047 & - & 0.5 \\
B (avg) & 29.60 & 10.19 & 0.832 & - & 10 \\
$(\alpha)$ & 24.39 & 11.26 & - & - & - \\
$(\gamma)$ & 30.04 & 9.62 & - & - & - \\
C (avg) & 28.63 & 10.45 & 0.498 & - & 35 \\
$(\alpha)$ & 26.66 & 9.79 & - & - & - \\
$(\gamma)$ & 31.36 & 8.22 & - & - & - \\
D (avg) & 29.99 & 10.19 & 0.305 & - & 65 \\
$(\alpha)$ & 28.13 & 10.33 & - & - & - \\
$(\gamma)$ & 32.25 & 8.81 & - & - & - \\
E & 21.50 & 9.86 & 0.330 & 6.23 & 98 \\
\hline
\end{tabular}

tematically examined under an optical microscope.

\section{RESULTS AND DISCUSSION}

Fig. 1 presents the potentiodynamic polarization curves for the alloys in deaerated $3.5 \% \mathrm{NaCl}$ solution at room temperature. The electrochemical parameters are summarized in Table 2. As can be seen, the corrosion potentials of the alloys varied in a very narrow range, from $-871 \mathrm{mV}$ to $-789 \mathrm{mV}$. The most noble potential was obtained for alloy $A$. Passivation was observed for all alloys. Except for alloy $E$, the width of the passive region was found to be a decreasing function of the ferrite content (falling from $360 \mathrm{mV}$ for alloy $A$ to $119 \mathrm{mV}$ for alloy $D$ ). The passive region became flatter and larger for alloy $E$. There were only small differences in the minimum passive currents for alloys $A$ to $D$. They were in the range of $17-35 \mu A / \mathrm{cm}^{2}$. On the other hand, the passive region of alloy $E$ lied below those of other alloys, with a minimum value of $4 \mu A / \mathrm{cm}^{2}$. Because of the increasing passive current of alloys $A$ to $E$, it appeared that a higher content of ferrite led to a higher sensitivity to the corrosion attack. In the case of alloy $E$, which was nearly fully ferritic, the addition of $6 \%$ of chromium was likely the reason for the decrease of the passive current and the broader passive region.

As for the pitting potential, the noblest potential was recorded for alloy $A$. When the ferrite content increased from alloy $B$ to $D$, the pitting potential became more negative. Alloy $E$ must be considered separately again, because of different shape of the polarization curve. Although the increase of the cur-

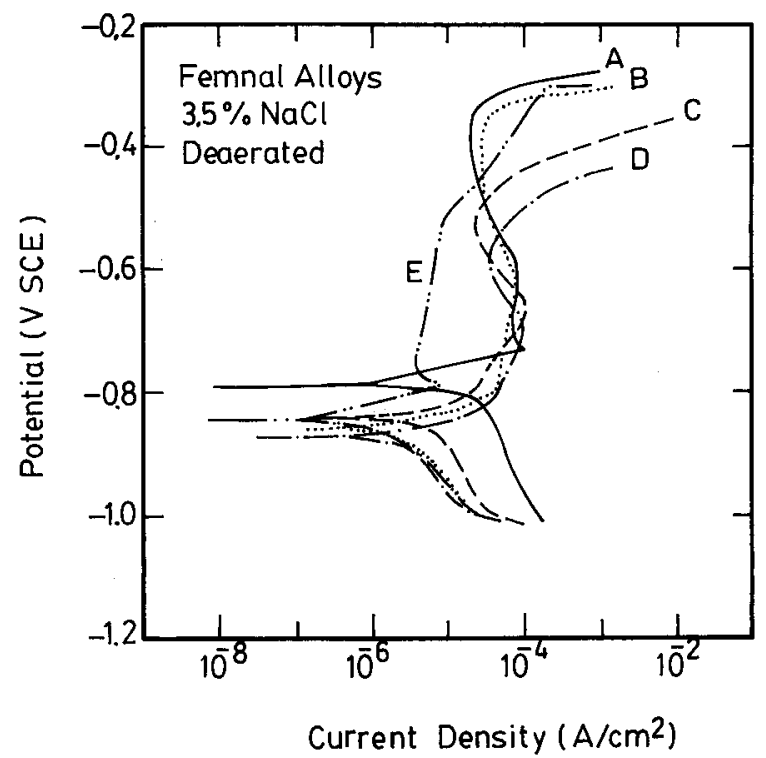

Fig. 1. Potentiodynamic polarization curves of the alloys in deaer ated $3.5 \% \mathrm{NaCl}$ solution. Scanning rate: $1 \mathrm{mV} / \mathrm{s}$. 
Table 2. Electrochemical Parameters of the Alloys in 3.5\% NaCl

\begin{tabular}{cccccc}
\hline Alloy & $\begin{array}{c}\text { Solution } \\
\text { treatment }\end{array}$ & $\begin{array}{c}\mathrm{E}_{\text {corr }} \\
(\mathrm{mV} \text { SCE })\end{array}$ & $\begin{array}{l}\mathrm{E}_{\mathrm{cr}} \\
(\mathrm{mV} \text { SCE })\end{array}$ & $\begin{array}{l}\mathrm{E}_{\mathrm{pp}} \\
(\mathrm{mV} \text { SCE })\end{array}$ & $\begin{array}{l}\mathrm{i}_{\mathrm{p}} \\
\left(\mu \mathrm{A} / \mathrm{cm}^{2}\right)\end{array}$ \\
\hline $\mathrm{A}$ & deaerated & -789 & -728 & -335 & 17 \\
$\mathrm{~B}$ & deaerated & -859 & -637 & -365 & 26 \\
$\mathrm{C}$ & deaerated & -839 & -668 & -505 & 23 \\
$\mathrm{D}$ & deaerated & -871 & -698 & -555 & 35 \\
$\mathrm{E}$ & deaerated & -840 & -790 & -520 & - \\
$\mathrm{A}$ & aerated & -325 & - & - & - \\
$\mathrm{B}$ & aerated & -382 & - & - & - \\
$\mathrm{C}$ & aerated & -400 & - & - & - \\
$\mathrm{D}$ & aerated & -452 & - & - & - \\
$\mathrm{E}$ & aerated & -354 & - & - & - \\
\hline
\end{tabular}

$\mathrm{E}_{\text {corr }}:$ corrosion potential

$E_{c r}$ : critical potential for active-passive transition

$\mathrm{E}_{\mathrm{pp}}$ : pitting potential

$i_{p} \quad$ : passive current density, minimum value

rent started at a quite negative value of $-520 \mathrm{mV}$, the curve was much less steep than the other alloys.

The influence of the scanning rate on the polarization curve was studied for alloy $D$. As can be seen from Fig.2, there was no difference in the corrosion potentials. In the passive region, a lower scanning rate led to a lower passive current. This result showed that the corrosion process, especially the passivation, was a time dependent process for this alloy. At a scanning rate of $10 \mathrm{mV} / \mathrm{s}$, there was no sufficient time for passivation. At $0.2 \mathrm{mV} / \mathrm{s}$, the width of the passive region became larger, compared with that for $1 \mathrm{mV} / \mathrm{s}$.

If tested in the aerated solution, the corrosion potentials of all alloys were shifted to more positive values approximately by $0.5 \mathrm{~V}$, as shown in Fig. 3. The corrosion potentials are also listed in Table 2 for comparison. They were again in a narrow interval, between $-325 \mathrm{mV}$ (alloy $A$ ) and $-452 \mathrm{mV}$ (alloy $D$ ). The higher ferrite content led to a lower value. Alloy $E$ was an exception. Its corrosion potential was increased to $-354 \mathrm{mV}$. The passivation region was not present for all alloys except that alloy $E$ seemed to have a small extended region. The potentials for rapid rise of current in the anodic region varied with the ferrite content, similar to the pitting potentials in the deaerated solution. On the other hand, alloy $E$ showed the highest resistivity to the pitting damage.

During the immersion test, specimens of alloys $A, B, C$, and $D$ were covered by a layer of stain soon after the immersion had begun. For these alloys, the color of the stain appeared to be darker and the stain became thicker for longer immersion time. For alloy

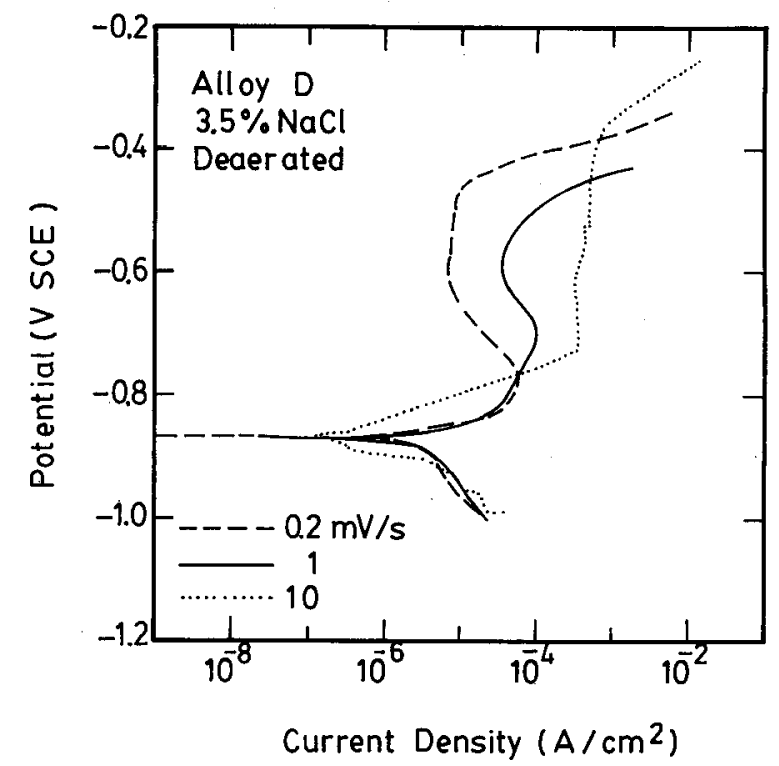

Fig. 2. Potentiodynamic polarization curves for alloy $D$ at differ ent scanning rates in deaerated solution.

$E$, on the other hand, even after 3 weeks of immersion test, no stain was observed at all on the surface except that some crevice corrosion took place near the fixing points. Some larger pits were also observed on the edges.

For the metallographic study, the stain was polished off and the surface was examined under an optical microscope. It was found that the darker stain was always originated from some pits. For the areas 


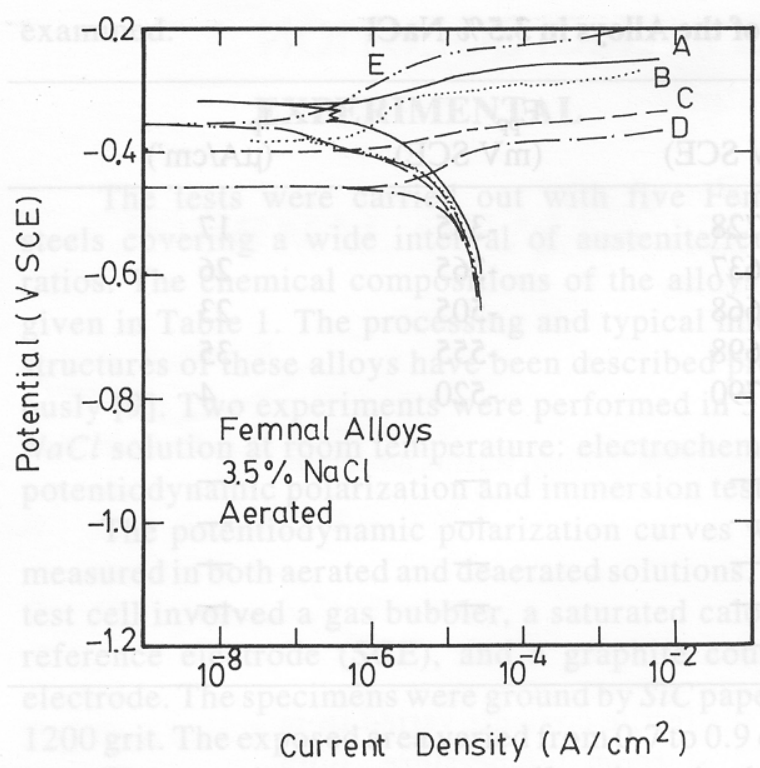

Fig. 3. Potentiodynamic polarization curves of the alloys in aer ated $3.5 \% \mathrm{NaCl}$ solution. Scanning rate: $\operatorname{lm} V / s$.

free of pitting, only a thin layer of stain was present. This implied that the general corrosion was not significant and pitting was the primary type of corrosion for alloys $A$ to $D$. The favorable sites for pit nucleation were the ferrite grains and the ferrite/austenite interfaces. Once nucleated, the pits would only grow within the ferrite grain or along the interface. For example, Fig. 4 shows the optical micrograph of alloy $C$ after seven days of immersion test. Most of the pits were positioned within the ferrite grains. Some were present at the interface. Since the ferrite grains were the preferential sites for pitting, the maximum size of the pits was limited by the grain size of the ferrite phase. For alloy $E$, except near the edge of the specimens, no pit was observed. This demonstrated the benefit of addition of $\mathrm{Cr}$ for the corrosion resistance.

\section{CONCLUSIONS}

1. For Femnal alloys, polarization tests indicated that higher content of ferrite led to a smaller passive region and a higher passive current. With $6.23 \% \mathrm{Cr}$ in alloy $E$, the passivation properties were greatly improved.

2. The passivation was dependent on the scanning rate. A lower scanning rate allowed more time for passivation.

3. During the immersion test, pitting was the primary type of corrosion. Pitting occurred preferentially in the ferrite grains or along the interface between ferrite and austenite. The severity of pitting increased with the ferrite content. However, alloy $E$ showed good resistance to pitting due to the addition of $\mathrm{Cr}$.

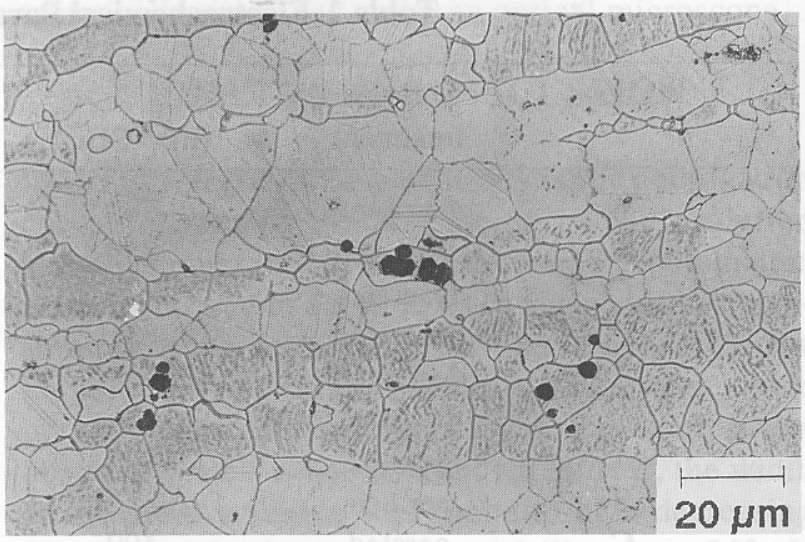

Fig. 4. Pitting morphology of alloy $C$ after immersion test for seven days.

\section{ACKNOWLEDGMENTS}

This research was supported by the National Science Council of the Republic of China under Contract Nos. NSC 81-0405-E-007-12 and NSC 82-0405E-007-052. The Femnal alloys were supplied by the Alloy Steel Laboratory, National Tsing Hua University, Taiwan.

\section{REFERENCES}

1. C. J. Altstetter, A. P. Bentley, J. W. Fourie and A. N. Kirkbride, Mat. Sci. Eng., vol. 82, p. 13, 1986.

2. J.G.Duh, S. H. Huarng, and C. M. Wan, Proceedings of 1 st CSIR(ROSA)-NSC(ROC) Met. Alloys and Ceramics Workshop, National Tsing Hua University, Hsinchu, Taiwan, Aug. 1983, p. 49.

3. S. C. Chang, Y. C. Pan and C. M. Wan, ibid., p. 77.

4. T. F. Liu and C. M. Wan, ibid., p.149.

5. J. C. Garcia, N. Rosas and R. T. Rioja, Met. Prog., vol. 122, No. 8, p. 47, 1982.

6. J. C. Benz and H. W. Leavenworth, Jr., J. Met., vol. 37 , No. 3, p. $36,1985$.

7. C. A. Pierpoint, T. S. Sudarshan, M. R. Louthan, Jr., and T. A. Place, 18th Annual Technical Meeting, Int. Metall. Soc., Denver, Colorado, July, 1985.

8. J. J. Chan and S. C. Chang, Corrosion, Vol. 44, p.209, 1988.

9. I. F. Tsu and T. P. Perng, Metall. Trans. A, Vol. 22A, p.215, 1991 .

10. S. C. Chang, T. S. Sheu and C. M. Wan, Proceedings of the 7th Int. Conf. on the Strength of Metals and Alloys, Canada, August 1985, p.1081.

11. S. T. Shih, I. F. Tsu and T. P. Perng, Metall. Trans. A, Vol. 24A, p.459, 1993.

12. S. C. Tjong, Werkstoffe und Korrosion, Vol.37, p.444, 1986. 
13. S. C. Tjong, Surf.Coat. Technol., Vol.28, p.181, 1986.

14. S.-T. Shih, C.-Y. Tai and T.-P. Perng, Corrosion, Vol. 49,p.130, 1993.

15. J. B. Duh, W. T. Tsai, J. T. Lee, Corrosion, Vol.44, p.810, 1988 .

16. W. T. Tsai, J. B. Duh, J. T. Lee, J. Mat. Sci., Vol.22, p. 3517, 1987 . 